\title{
An Algorithm to Stratify the Risk of Postoperative Emotional Distress in Cancer Patients with Advanced Metastatic Spinal Disease
}

This article was published in the following Dove Press journal: Psychology Research and Behavior Management

\author{
Wenjing Zheng' \\ Mingxing Lei ${ }^{2}$ \\ Yaosheng Liu' \\ Xin $\mathrm{Lu}^{3}$ \\ Dan $\mathrm{Yu}^{4}$ \\ Xin Zhang ${ }^{5}$
}

'Department of Orthopedic Surgery, The Fifth Medical Center of Chinese PLA General Hospital, Beijing, People's Republic of China; ${ }^{2}$ Department of Orthopedic Surgery, The Hainan Hospital of Chinese PLA General Hospital, Sanya, People's Republic of China; ${ }^{3}$ Department of General Surgery, The Fifth Medical Center of Chinese PLA General Hospital, Beijing, People's Republic of China; ${ }^{4}$ Department of Neurosurgery, The Fifth Medical Center of Chinese PLA General Hospital, Beijing, People's Republic of China; ${ }^{5}$ Nursing Department, The Fifth Medical Center of Chinese PLA General Hospital, Beijing, People's Republic of China
Correspondence: Xin Zhang

Nursing Department, The Fifth Medical

Center of Chinese PLA General Hospital, 100 the 4thWest Ring Middle Road,

Fengtai District, Beijing 10007I, People's

Republic of China

Tel/Fax +86-10-933045

Email zhangxinliu@sina.com
Purpose: We wish (1) to assess what variables are significantly associated with postoperative emotional distress in patients with the metastatic spinal disease after surgery and (2) to develop and validate an algorithm to stratify patients at risk of postoperative emotional distress.

Patients and Methods: We retrospectively enrolled 171 patients with the metastatic spinal disease treated with surgery. Twelve potential variables were used to analyze postoperative emotional distress. Postoperative emotional well-being was measured using the Hospital Anxiety and Depression Scales (HADS). Significant variables were included in the algorithm and assigned scores based on odds ratios (ORs) from the multiple logistic regression analysis. The predictive performance of the risk algorithm was validated on the basis of discrimination and calibration.

Results: Twenty-six (15.20\%) patients had a HADS of 19 points or more. Of all the 12 variables, age $(\mathrm{P}=0.06)$, marital status $(\mathrm{P}=0.02)$, primary cancer types $(\mathrm{P}=0.004)$, and physical well-being $(\mathrm{P}=0.006)$ were included in the algorithm. This algorithm ranged from 0 to 24. Higher scores represented higher rates of postoperative emotional distress. Patients were stratified into three risk groups: patients in the group A had scores of 0 to 9 and the rate of postoperative emotional distress was only $1.14 \%$, patient in the group B had scores of 10 to 15 and the rate of postoperative emotional distress was $21.31 \%$, and patient in the group $\mathrm{C}$ had scores of 16 to 24 and the rate of postoperative emotional distress was up to $54.55 \%$. The area under the receiver operating characteristic curve (AUROC) for the algorithm was 0.84 , and the correct classification rate was $81.3 \%$.

Conclusion: Postoperative emotional distress is common in patients with the metastatic spinal disease after surgery. We propose and validate an algorithm that can be used as a potential screening tool to identify patients at high risk of postoperative emotional distress. Keywords: metastatic spinal disease, decompressive surgery, anxiety, depression, emotional distress, risk variables

\section{Introduction}

Cancer is a significant public health problem and is the leading cause of death in China ${ }^{1}$ and worldwide. ${ }^{2}$ Its incidence and mortality are rapidly growing, and it was estimated 18.1 million new cancer cases and 9.6 million cancer deaths in 2018 worldwide. $^{2}$ As a severe complication of cancer, the metastatic spinal disease is a life-threatening disease that frequently presents severe back pain, radiculopathy, weakness, sensory changes, and sphincter incontinence, ${ }^{3}$ of which significantly compromises the patient's quality of remaining life. Decompressive surgery is one of the standard therapeutic 
strategies for this disease to obtain pain relief and functional improvement. ${ }^{4}$ However, anxiety and depression are the most common emotional disorders among advanced cancer patients, especially those treated with surgery. Studies have found that $29-55 \%$ of advanced cancer patients suffered from depression, 5,6 and up to $44-65 \%$ of patients had anxiety. ${ }^{6,7}$ The actual proportions of anxiety and depression may be higher because both emotional disorders are often underestimated. ${ }^{7}$ Therefore, more attention to mental healthcare should be paid to advanced cancer patients and patients with the metastatic spinal disease to improve the patient's quality of remaining life.

It would help select individual healthcare strategies in advanced cancer patients after understanding which of the patients are at risk for postoperative emotional distress. Namely, stratification of patients at risk of postoperative anxiety and depression can help guide healthcare interventions. Notably, some risk variables have been proved to be associated with anxiety and depression in advanced cancer settings. In detail, gender, ${ }^{6}$ performance status, ${ }^{6,8,9}$ primary cancer type, ${ }^{6,10}$ overall well-being, ${ }^{6}$ history of mental health disorders, ${ }^{11}$ and the amount of social support received $^{12,13}$ could be significant predictors of anxiety and depression in general cancer populations. In metastatic bone disease setting, poor prognostic cancer and pathological fracture were significantly associated with more anxiety, and being single and pathological fracture was significantly associated with more depression. ${ }^{14}$ However, specific recommendations for preventing and reducing postoperative anxiety and depression in advanced cancer patients with the metastatic spinal disease have not been proposed mainly because of the inadequate investigation about population-specific risk factors in these patients.

Moreover, some risk algorithms have been developed to predict the prognosis of advanced cancer patients with metastatic spinal disease. These algorithms included significant variables associated with corresponding outcomes, such as survival time, ${ }^{15-17}$ postoperative complications, and functional outcomes. ${ }^{18,19}$ These algorithms could serve as a useful clinical tool to identify patients at high risk of poor prognosis and subsequently guide therapeutic strategies. A risk algorithm to predict postoperative psychological distress could also be used to select patients at high risks of emotional problems, and corresponding interventions could be early given to prevent and reduce emotional problems. However, to our knowledge, there is no research proposing a risk algorithm to predict postoperative psychological distress, especially in advanced cancer patients after decompressive surgery.

Therefore, we wish (1) to assess what variables were significantly associated with postoperative anxiety and depression in advanced cancer patients with the metastatic spinal disease after decompressive surgery, and (2) to develop and validate an algorithm to stratify patients at risks of postoperative emotional distress.

\section{Patients and Methods}

\section{Patients}

We retrospectively analyzed 359 cancer patients with advanced metastatic spinal disease admitted for surgery in our hospital between January 2013 and January 2019. Of all the patients, 171 patients were included in the study (Figure 1). The metastatic spinal disease was diagnosed by magnetic resonance imaging or myelography. Patients treated with surgery mainly due to spinal pain, mechanical instability, or neurological problems and all patients were treated by the same team of spine surgeons. Inclusive criteria: (1) patients were treated with a decompressive surgery at our department; (2) patients had an age of more than 18 years old; (3) patients had complete records. Exclusive criteria: (1) patients were treated with conservative treatments or percutaneously vertebroplasty; (2) patients had a primary bone tumor of the spine; (3) patients were diagnosed with mental illness; (4) patients had intramedullary metastases. The Ethics Committee Board of the Fifth Medical Center of Chinese PLA General Hospital approved the study protocol and waived informed consent form since the study was retrospective in nature. Patient's data are confidential and complied with the Declaration of Helsinki.

\section{Primary Endpoint: Postoperative Emotional Well-Being}

Postoperative emotional well-being was measured using Hospital Anxiety and Depression Scales (HADS) after surgery before discharging from the hospital. The HADS has been widely used to identify patients with anxiety and depression during hospitalization. ${ }^{20}$ It includes two independent measures: the anxiety scales scored from 0 to 21 , and the depression scales also scored from 0 to 21 . A combined score of the two measures of 19 or more has been reported to have a diagnosis of emotional distress, and the sensitivity and the specificity were $68 \%$ and $67 \%$, respectively, according to the literature. ${ }^{21}$ This tool 


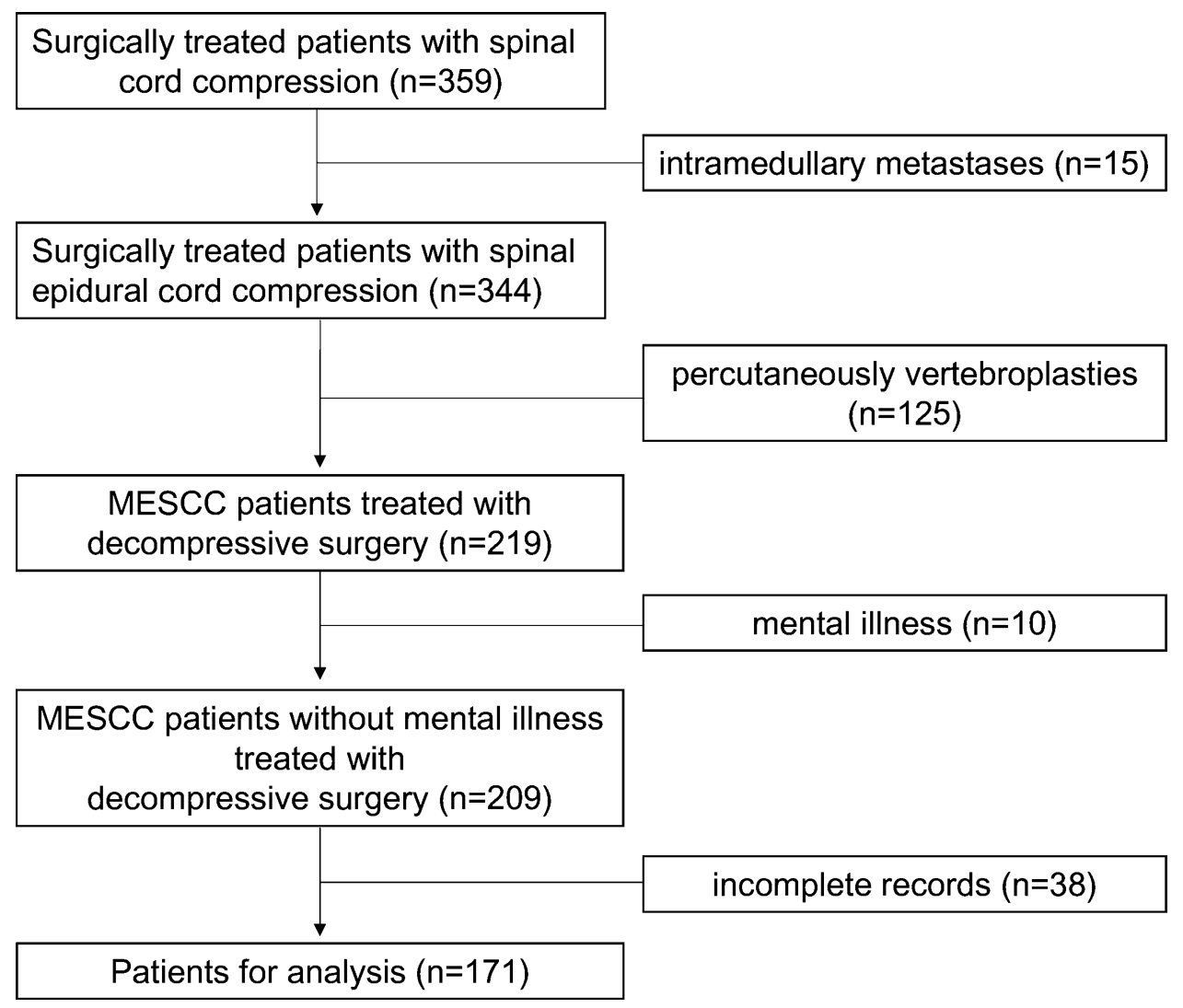

Figure I Patient's flowchart.

Abbreviation: MESCC, metastatic epidural spinal cord compression.

had been validated for use in cancer patients in previous researches, and researchers concluded this tool was valid and reliable instrument. ${ }^{22,23}$

\section{Potential Risk Variables}

We chose potential risk variables based on literature reviews and the availability of variables in the medical records. Preoperative candidate variables were identified to predict postoperative emotional well-being. At last, 12 potential risk variables were included as potential risk variables, including age ( $\leqq 50$ years vs $51-60$ years vs 61-70 years vs $\geqq 71$ years), gender (male vs female), marital status (living with a partner vs separated/ divorced/widowed vs single), preoperative caregiver(s) (spouse/children vs others), education level ( $<$ College vs $\geqq$ College), occupation (yes vs no), primary cancer types (slow growth vs moderate growth vs rapid growth), preoperative KPS ( $\leqq 50$ vs $>50$ ), body mass index (underweight vs healthy weight vs overweight vs obesity), number of chronic diseases ( $<3$ vs $\geqq 3$ ), preoperative ambulatory status (ambulatory vs not ambulatory), and physical well-being (yes vs no). Primary cancer types were classified into three groups, which were consistent with previous research. ${ }^{24}$ Preoperative KPS (Karnofsky performance status), ${ }^{6,25}$ ranging from 0 to 100 , was obtained from self-reports. Body mass index was classified into four groups according to WHO guidelines. Ambulatory status was evaluated by Frankel scores. ${ }^{26}$ Patients with Frankel A to $\mathrm{C}$ could not walk, while patients with Frankel D and E could walk. Physical wellbeing included six items: pain, tiredness, nausea, drowsiness, lack of appetite, or dyspnea. If a patient had at least three elements, the patients were classified into the worse physical well-being group.

\section{Development of the Risk Algorithm}

We used multivariate analysis (method=stepwise) to screen the 12 variables, as mentioned above, and four variables were included in the risk algorithm. Although age was not statistically significant $(\mathrm{P}=0.06)$, it was significantly associated with depression, according to other literature. ${ }^{6}$ Therefore, the variable of age was also included in the algorithm. The ORs (odds ratios), rounding off to the nearest integer, were used to assign a score to 
each included variable. Each patient's total score was obtained from the combined scores from all included four variables in the algorithm. The rates of emotional distress were also calculated in each overall score.

\section{Validation of the Risk Algorithm}

The predictive performance of the risk algorithm was evaluated on the basis of discrimination and calibration. Discrimination was the ability to separate patients who had postoperative emotional distress and who had not. Calibration was the consistency between the observed and predicted postoperative psychological distress risk. The area under the receiver operating characteristic curve (AUROC) was used to calculate the risk algorithm's discrimination in the study. ${ }^{27}$ Higher AUROC value indicates better discrimination of the risk algorithm: an AUROC value of more than 0.7 indicates useful algorithm discrimination, more than 0.8 indicates good algorithm discrimination, and more than 0.9 indicates excellent algorithm discrimination. Regarding the calibration evaluation of the risk algorithm, the Hosmer-Lemeshow goodness-of-fit test was used. A P-value of this test more than 0.05 indicates a good agreement between the predicted and observed risks.

\section{Statistical Analysis}

The patient's demographics were collected and presented in the study. The risk algorithm was developed based on significant variables identified by the multiple logistic regression analysis (method=stepwise). The correct classification rate, sensitivity, specificity, false positive rate, and false negative rate of the model with and without the age variable were also calculated in the study. All analyses were performed using SAS 9.2 software for Windows XP (SAS Institute Inc., Cary, NC). A P value of 0.05 or less was considered statistically significant.

\section{Results}

\section{Patient's Demographics}

Table 1 shows the demographic data of all participants. Of all the 171 patients treated with surgery, 91 (53.22\%) were male, and $80(46.78 \%)$ were female. The mean age was 61.14 years (range, 42.00-78.00 years). Twenty-six $(15.20 \%)$ patients had a HADS of 19 or more. Regarding marital status and caregivers, $56(32.75 \%)$ patients lived with a partner, and 96 (56.14\%) patients obtained care from their spouse or children. The most common cancer
Table I Patient's Demographics

\begin{tabular}{|c|c|}
\hline Age (years) & Patients $(N=|7|)$ \\
\hline$\leqq 50$ & $14.04 \%(24 / 17 \mid)$ \\
\hline $51-60$ & $30.99 \%(53 /|7|)$ \\
\hline $6 I-70$ & $34.50 \%(59 / 171)$ \\
\hline$\geqq 71$ & $20.47 \%(35 / 17 I)$ \\
\hline \multicolumn{2}{|l|}{ Gender } \\
\hline Male & $53.22 \%(91 / 17 I)$ \\
\hline Female & $46.78 \%(80 / 17 I)$ \\
\hline \multicolumn{2}{|l|}{ Marital status } \\
\hline Living with partner & $32.75 \%(56 / 17 I)$ \\
\hline Separated/divorced/widowed & $50.88 \%(87 / 17 I)$ \\
\hline Single & $16.37 \%(28 /|7|)$ \\
\hline \multicolumn{2}{|l|}{ Preoperative caregiver(s) } \\
\hline Others & $43.86 \%(75 / 17 I)$ \\
\hline Spouse or Children & $56.14 \%(96 / 171)$ \\
\hline \multicolumn{2}{|l|}{ Education level } \\
\hline$<$ College & $76.02 \%(|30 /| 7 \mid)$ \\
\hline$\geq$ College & $23.98 \%(4 I / I 7 I)$ \\
\hline \multicolumn{2}{|l|}{ Occupation } \\
\hline Yes & $29.24 \%(50 / I 7 I)$ \\
\hline No & $70.76 \%(|2| /|7|)$ \\
\hline \multicolumn{2}{|l|}{ Primary cancer type } \\
\hline Slow growth & $63.74 \%(109 / 171)$ \\
\hline Moderate growth & $12.87 \%(22 / 17 \mid)$ \\
\hline Rapid growth & $23.39 \%(40 / 17 I)$ \\
\hline \multicolumn{2}{|l|}{ Preoperative KPS } \\
\hline$\leq 50$ & $42.69 \%(73 / I 7 I)$ \\
\hline$>50$ & $57.31 \%(98 / I 7 I)$ \\
\hline \multicolumn{2}{|l|}{ Body mass index } \\
\hline Underweight & $26.90 \%(46 / I 7 I)$ \\
\hline Healthy weight & $49.71 \%(85 / 17 I)$ \\
\hline Overweight & $18.13 \%(3|/| 7 \mid)$ \\
\hline Obesity & $5.26 \%(9 / 171)$ \\
\hline \multicolumn{2}{|l|}{ Number of chronic diseases } \\
\hline$<3$ & $62.57 \%(107 / 171)$ \\
\hline$\geq 3$ & $37.43 \%(64 / 17 I)$ \\
\hline \multicolumn{2}{|l|}{ Preoperative ambulatory status } \\
\hline Ambulatory & $71.35 \%(122 / 17 \mid)$ \\
\hline Not ambulatory & $28.65 \%(49 / 17 I)$ \\
\hline \multicolumn{2}{|l|}{ Physical well-being * } \\
\hline Yes & $63.74 \%(109 / 171)$ \\
\hline No & $36.26 \%(62 / I 7 I)$ \\
\hline \multicolumn{2}{|l|}{ Severity of anxiety and depression } \\
\hline$<19$ & $84.80 \%(|45 /| 7 \mid)$ \\
\hline$\geq 19$ & $15.20 \%(26 /|7|)$ \\
\hline
\end{tabular}

Notes: *Indicates physical well-being items included pain, tiredness, nausea, drowsiness, lack of appetite, or dyspnea. If a patient had at least 3 items, the patients was classified into the worse physical well-being group.

Abbreviation: KPS, Karnofsky performance status. 
type was the slow growth of cancers, which occurred in $109(63.74 \%)$ patients. In detail, in patients with the slow growth of cancers, 41 patients had breast cancers, 29 had prostate cancers, 19 had thyroid cancers, and 20 had other cancers.

\section{Factor Analysis}

We screened 12 preoperative potential risk variables for postoperative HADS (Table 2). In the univariate analysis, age $(\mathrm{P}=0.01)$, marital status $(\mathrm{P}<0.001)$, primary cancer types $(\mathrm{P}=0.035)$, preoperative KPS $(\mathrm{P}=0.004)$, preoperative ambulatory status $(\mathrm{P}=0.003)$, and physical well-being $(\mathrm{P}<0.001)$ were significantly associated with postoperative HAD. In the multivariate analysis, marital status $(\mathrm{P}=0.02)$, primary cancer types $(\mathrm{P}=0.004)$, and physical well-being $(\mathrm{P}=0.006)$ were significantly associated with postoperative HAD, while preoperative KPS $(\mathrm{P}=0.24)$ and preoperative ambulatory status $(\mathrm{P}=0.44)$ lost significance. The abovementioned three significant variables were included in the algorithm. Although age $(\mathrm{P}=0.06)$ was not statistically significant, it also included in the algorithm because its $\mathrm{P}$ value was almost near 0.05 . Therefore, the four variables were included in the algorithm.

\section{Algorithm Development}

The ORs of the four significant variables were rounded off to the nearest integer and were used to assign a score to each included variable (Table 3 ). For example, the OR of the age variable was 1.78 , and the rounded value was 2.00 . Patients with an age of fewer than 50 years were assigned 0,51 to 60 years were assigned 2 points, 61 to 70 years were assigned 4 points, and 71 or more were assigned 6 points. The same assignment rule was also performed to variables of marital status and primary cancer types. However, we assigned patients without physical wellbeing 6 points, although the OR of the variable was 4.88 . It would be easier to remember the risk algorithm if all the four included variables were of the utmost 6 points. Therefore, this risk mode ranged from 0 to 24 points.

Each patient's overall score was obtained from the combined scores from all included four variables in the algorithm (Table 4). For example, a 65-years-old (4 points) patient who lived with her/his partner ( 0 points) was diagnosed with rapid growth cancer (6 points), and he/she had the symptoms of back pain, nausea, and drowsiness ( 6 points). The total score of the patient was 16 points. The number of patients in each overall score was normally distributed (Figure 2). The rates of postoperative emotional distress were calculated in each overall score, which indicated that higher scores represented higher rates of postoperative emotional distress. We classified those patients into three risk groups. Patients in the group A with scores of 0 to 9 had a rate of postoperative emotional distress of $1.14 \%$, and this number increased to $21.31 \%$ among patients in the group B with scores of 10 to 15 . In comparison, patients in the group $\mathrm{C}$ with scores of 16 to 24 had the highest rate of postoperative emotional distress, and the number was up to $54.55 \%$.

\section{Algorithm Validation}

The AUROC value for the risk algorithm with the age variable was 0.84 (Figure 3 and Table 5), and the correct classification rate was $81.3 \%$. The sensitivity and specificity of the algorithm were $61.5 \%$ and $84.8 \%$, respectively, and the false positive rate and false negative rate of the algorithm were $57.9 \%$ and $7.5 \%$, respectively. The AUROC value for the risk algorithm without the age variable was 0.82 (Figure 3 and Table 5), and the correct classification rate was $70.2 \%$. The algorithm's sensitivity and specificity were $53.8 \%$ and $73.1 \%$, respectively, and the false positive rate and false negative rate of the algorithm were $73.6 .9 \%$ and $10.2 \%$, respectively. The $\mathrm{P}$ values obtained from the goodness-offit test were 0.76 for the risk algorithm including the variable of age and 0.06 for the risk algorithm excluding the variable of age, respectively, which indicated that the risk algorithm including the variable of age had better calibration than the risk algorithm excluding the variable of age.

\section{Discussion}

It would help clinical decision-making fully understand which of the patients are more likely to develop anxiety and depression so that postoperative deterioration can be preoperatively anticipated and potential medical interventions can be performed early. Previous studies have identified risk factors for anxiety and depression in the advanced cancer setting. We first found that younger age, being single, rapid growth cancer, and reduced physical well-being were independently associated with worse anxiety and depression in a specific population in advanced cancer patients with the metastatic spinal disease after decompressive surgery. Furthermore, we developed and validated a risk algorithm to preoperatively predict the risk of postoperative anxiety and depression based on the above-mention four significant variables. 
Table 2 Univariate and Multivariate Analyses of Variables for Postoperative Emotional Distress in MESCC Patients Treated with Decompressive Surgery

\begin{tabular}{|c|c|c|c|c|c|}
\hline \multirow{2}{*}{ Variables } & \multirow[t]{2}{*}{$\mathbf{n}$} & \multicolumn{2}{|c|}{ Simple Logistic Regression } & \multicolumn{2}{|c|}{ Multiple Logistic Regression } \\
\hline & & OR $(95 \% \mathrm{Cl})$ & $\mathbf{P}$ & OR $(95 \% \mathrm{Cl})$ & $\mathbf{P}$ \\
\hline \multicolumn{6}{|l|}{ Age (years) } \\
\hline$\leqq 50$ & 24 & $1.89(1.17-3.07)$ & 0.01 & $1.78(0.98-3.25)$ & 0.06 \\
\hline $5 I-60$ & 53 & & & & \\
\hline $6 \mathrm{I}-70$ & 59 & & & & \\
\hline$\geqq 71$ & 35 & & & & \\
\hline \multicolumn{6}{|l|}{ Gender } \\
\hline Male & 91 & $0.97(0.42-2.24)$ & 0.94 & $1.30(0.4 I-4.10)$ & 0.66 \\
\hline Female & 80 & & & & \\
\hline \multicolumn{6}{|l|}{ Marital status } \\
\hline Living with partner & 56 & $3.54(1.79-7.00)$ & $<0.001$ & $2.69(1.17-6.21)$ & 0.02 \\
\hline Separated/divorced/widowed & 87 & & & & \\
\hline Single & 28 & & & & \\
\hline \multicolumn{6}{|l|}{ Preoperative caregiver(s) } \\
\hline Others & 75 & $1.34(0.58-3.09)$ & 0.49 & $2.14(0.7 \mid-6.45)$ & 0.17 \\
\hline Spouse or children & 96 & & & & \\
\hline \multicolumn{6}{|l|}{ Education level } \\
\hline$<$ College & 130 & $0.83(0.32-2.15)$ & 0.70 & $0.67(0.20-2.28)$ & 0.52 \\
\hline$\geq$ College & 41 & & & & \\
\hline \multicolumn{6}{|l|}{ Occupation } \\
\hline Yes & 50 & I.14(0.45-2.92) & 0.78 & $0.78(0.23-2.59)$ & 0.68 \\
\hline No & 121 & & & & \\
\hline \multicolumn{6}{|l|}{ Primary cancer types } \\
\hline Slow growth & 109 & $1.65(1.04-2.62)$ & 0.035 & $2.62(1.36-5.03)$ & 0.004 \\
\hline Moderate growth & 22 & & & & \\
\hline Rapid growth & 40 & & & & \\
\hline \multicolumn{6}{|l|}{ Preoperative KPS } \\
\hline$\leq 50$ & 73 & $3.68(1.50-9.04)$ & 0.004 & $2.33(0.56-9.64)$ & 0.24 \\
\hline$>50$ & 98 & & & & \\
\hline \multicolumn{6}{|l|}{ Body mass index } \\
\hline Underweight & 46 & $1.19(0.72-1.96)$ & 0.51 & $1.40(0.70-2.80)$ & 0.34 \\
\hline Healthy weight & 85 & & & & \\
\hline Overweight & 31 & & & & \\
\hline Obesity & 9 & & & & \\
\hline \multicolumn{6}{|l|}{ Number of chronic diseases } \\
\hline$<3$ & 107 & $1.84(0.80-4.27)$ & 0.15 & $\mathrm{I} .45(0.47-4.5 \mathrm{I})$ & 0.52 \\
\hline$\geq 3$ & 64 & & & & \\
\hline \multicolumn{6}{|l|}{ Preoperative ambulatory status } \\
\hline Ambulatory & 122 & $3.67(1.55-8.66)$ & 0.003 & $1.76(0.42-7.30)$ & 0.44 \\
\hline Not ambulatory & 49 & & & & \\
\hline \multicolumn{6}{|l|}{ Physical well-being * } \\
\hline Yes & 109 & $6.44(2.52-16.43)$ & $<0.001$ & $4.88(1.57-15.20)$ & 0.006 \\
\hline No & 62 & & & & \\
\hline
\end{tabular}

Notes: *Indicates physical well-being items included pain, tiredness, nausea, drowsiness, lack of appetite, or dyspnea. If a patient had at least 3 items, the patients was classified into the worse physical well-being group.

Abbreviations: KPS, Karnofsky performance status; MESCC, metastatic epidural spinal cord compression; OR, odds ratio; Cl, confident interval. 
Table 3 An Algorithm to Predict Postoperative Emotional Distress in MESCC Patients After Decompressive Surgery

\begin{tabular}{|l|l|l|}
\hline Prognostic Factors & OR & Scores \\
\hline Age (years) & I.78 & \\
$<50$ & & 0 \\
$51-60$ & & 4 \\
$61-70$ & & 6 \\
$>71$ & 2.69 & \\
\hline Marital status & & 0 \\
Living with partner & & 3 \\
Separated/divorced/widowed & 6 \\
Single & 2.62 & 0 \\
\hline Primary cancer types & & 3 \\
Slow growth & & 6 \\
Moderate growth & & \\
Rapid growth & 4.88 & 0 \\
\hline Physical well-being $*$ & & 6 \\
\hline Yes & & \\
No & & \\
\hline
\end{tabular}

Notes: *Indicates physical well-being items included pain, tiredness, nausea, drow siness, lack of appetite, or dyspnea. If a patient had at least 3 items, the patients was classified into the worse physical well-being group.

Abbreviations: MESCC, metastatic epidural spinal cord compression; OR, odds ratio.

Table 4 The Number of Patients and Rates of Emotional Distress in Each Score

\begin{tabular}{|c|c|c|c|c|}
\hline Scores & $\begin{array}{l}\text { Patients } \\
(n=|7|)\end{array}$ & $\begin{array}{l}\text { Rates of ED in } \\
\text { Each Score }\end{array}$ & Groups & $\begin{array}{l}\text { Rates of ED in } \\
\text { Each Group }\end{array}$ \\
\hline 0 & 2 & $0.00 \%(0 / 2)$ & A & $1.14 \%(1 / 88)$ \\
\hline 2 & 8 & $0.00 \%(0 / 8)$ & A & \\
\hline 3 & 6 & $0.00 \%(0 / 6)$ & A & \\
\hline 4 & 11 & $0.00 \%(0 / 11)$ & A & \\
\hline 5 & 19 & $0.00 \%(0 / 19)$ & A & \\
\hline 6 & 8 & $0.00 \%(0 / 8)$ & A & \\
\hline 7 & 7 & $0.00 \%(0 / 7)$ & A & \\
\hline 8 & 10 & $10.00 \%(1 / 10)$ & A & \\
\hline 9 & 17 & $0.00 \%(0 / 17)$ & A & \\
\hline 10 & 17 & $23.53 \%(4 / 17)$ & B & $21.31 \%(13 / 61)$ \\
\hline II & 11 & $18.18 \%(2 / I I)$ & B & \\
\hline 12 & 5 & $0.00 \%(0 / 5)$ & B & \\
\hline 13 & 11 & $18.18 \%(2 / 11)$ & B & \\
\hline 14 & 4 & $50.00 \%(2 / 4)$ & B & \\
\hline 15 & 13 & $23.08 \%(3 / 13)$ & B & \\
\hline 16 & 9 & $55.56 \%(5 / 9)$ & C & $54.55 \%(12 / 22)$ \\
\hline 18 & 3 & $66.67 \%(2 / 3)$ & C & \\
\hline 19 & 2 & $0.00 \%(0 / 2)$ & C & \\
\hline 20 & 1 & $100.00 \%(1 / 1)$ & C & \\
\hline 21 & 3 & $33.33 \%(1 / 3)$ & C & \\
\hline 22 & 2 & $50.00 \%(1 / 2)$ & C & \\
\hline 24 & 2 & $100.00 \%(2 / 2)$ & C & \\
\hline
\end{tabular}

Abbreviation: ED, emotional distress.
Patients with younger age were more prone to develop emotional problems. Studies have concluded that younger patients were significantly more anxious than older patients in advanced cancer setting. ${ }^{6,28}$ We speculate that younger advanced cancer patients may suffer from more traumatic emotional stress when receiving a major surgery for a serious complication of advanced cancers because younger patients have greater responsibilities for their families and more unfinished life goals. ${ }^{29}$ Besides, according to previous theory, ${ }^{30}$ older people have obtained increased wisdom and "emotional regulation", which may help them to better adapt to difficult situations and cope with life's challenges. However, a study found that age was not significantly associated with depression based on univariate and multivariate analysis. ${ }^{28}$ The variation can be attributed to different samples and methods of assessment. The above-mentioned studies included patients with age of 65 or more, and the study was designed to investigate the relationship between age and emotional problems in cancer patients not especially in advanced cancer patients with metastatic spinal disease.

Living with a partner was found to be positive with less anxiety and depression. We speculate that these patients can have more opportunities to benefit from the social support of their partners. Social support plays a crucial role in alleviating emotional distress under general cancer settings $^{28,31}$ and colorectal cancer-specific patients. ${ }^{31}$ Being consistent with our study, previous studies also showed an association between being single and more anxious and depressed. Vliet et al ${ }^{14}$ found that being single was significantly associated with depression in metastatic bone disease. Besides, this study also concluded that poor prognosis cancers and pathologic fractures were significantly associated with more anxiety.

The primary cancer type was an independent predictor of postoperative anxiety and depression. Salvo et al ${ }^{6}$ found that patients with primary lung cancer were more vulnerable to depressed and anxious feelings. In contrast, primary prostate cancer patients were significantly less likely to report depression and anxiety after analyzing 1439 advanced cancer patients. In the present study, we also confirmed that the primary cancer type was significantly associated with postoperative anxiety and depression. The primary cancer type was classified into three groups according to the previous study. Prostate cancer had different prognoses according to hormone-dependent status, and lung cancer treated with targeted drugs also showed a better outcome. Therefore, in the study, hormone-dependent prostate cancer was assigned to 


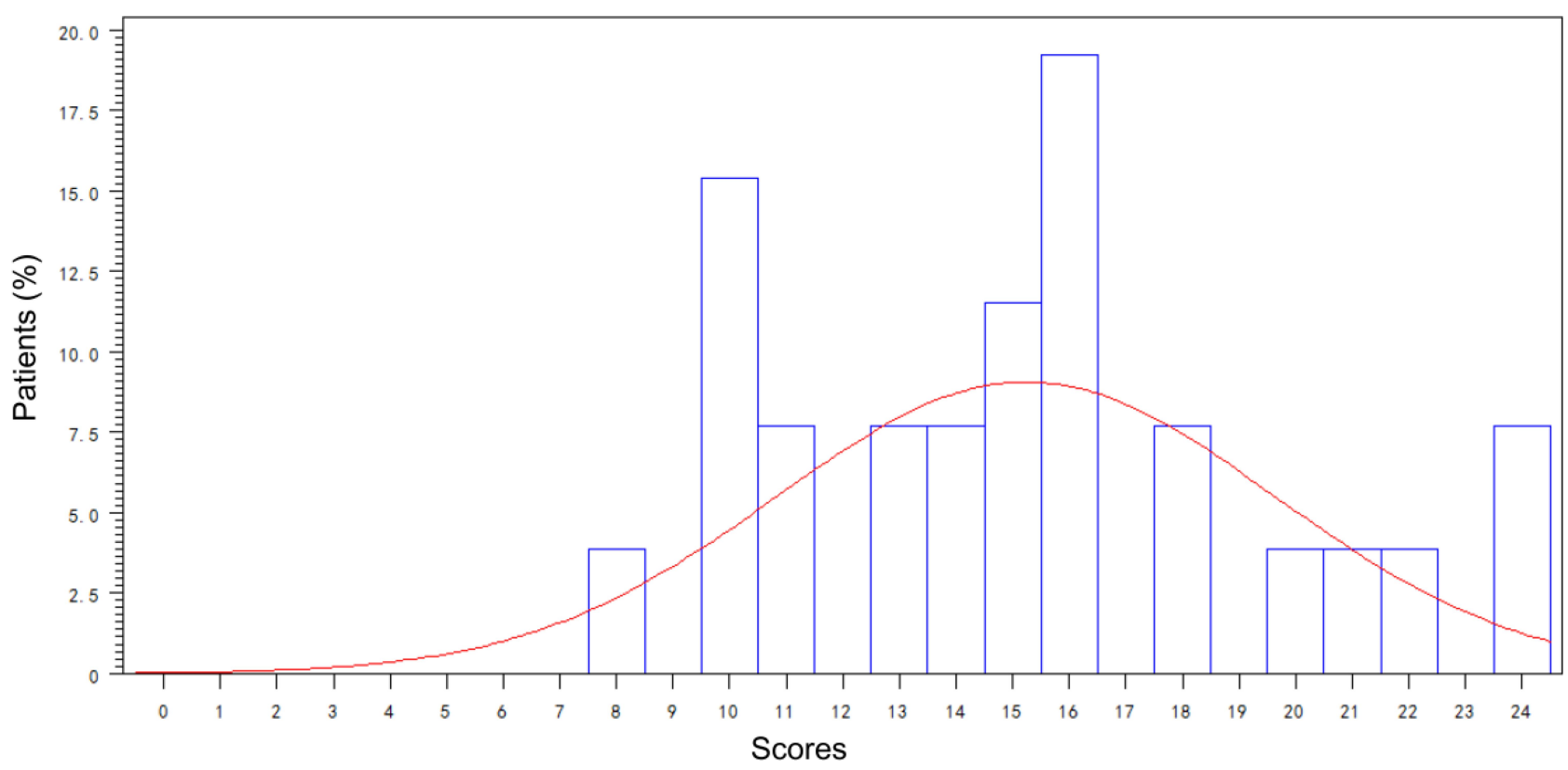

Figure 2 The histogram of the distribution of patients in each score (\%). The blue rectangles represent the proportions of patients in each score. The red line indicates the number of patients in different scores was normally distributed.

A

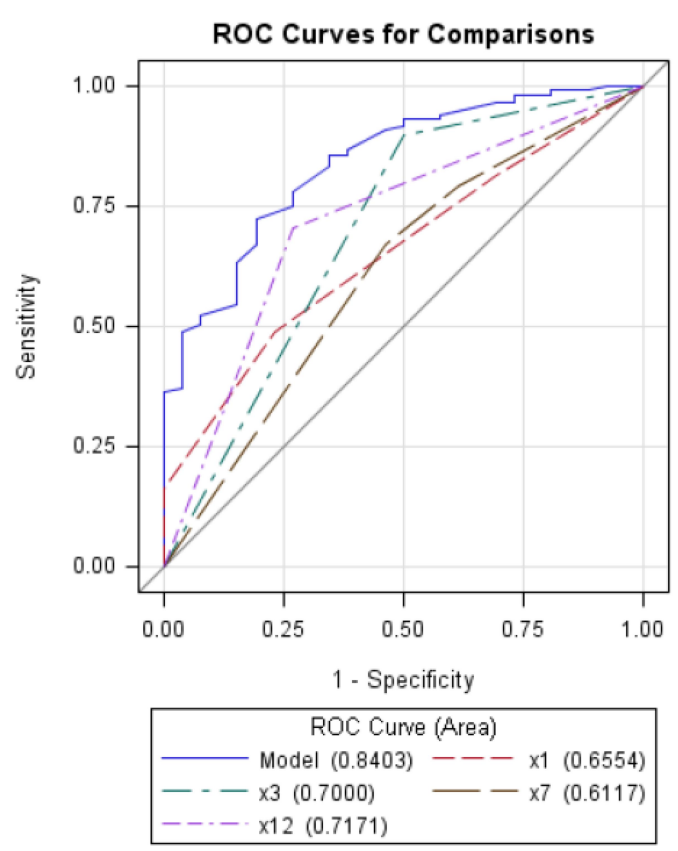

B

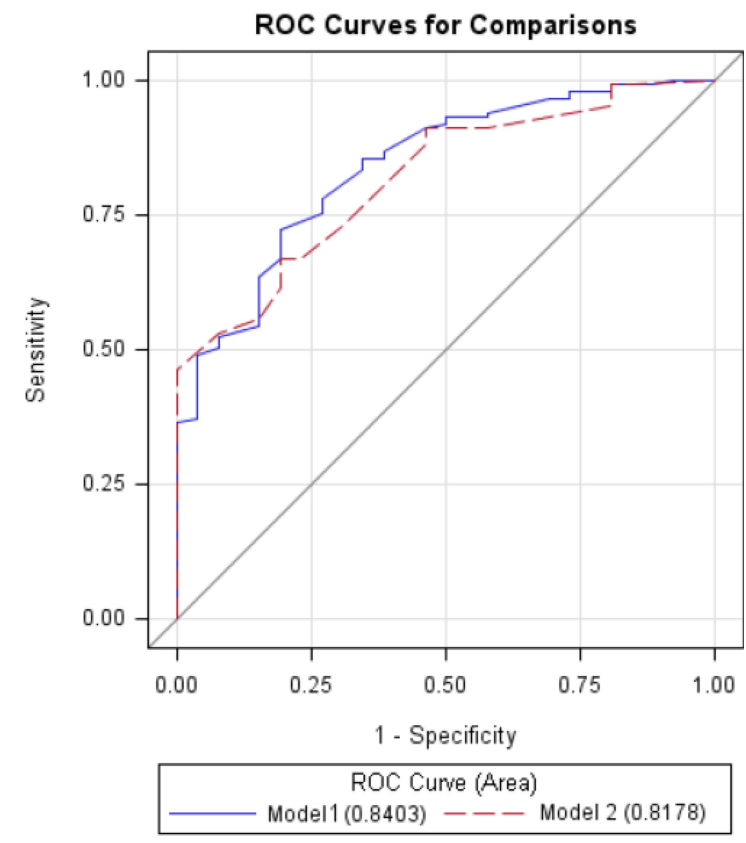

Figure 3 (A) ROC Curves for the algorithm and the four included variables. The $C$ value of the algorithm was 0.84 (the blue line in the picture). $X I$ (the red line) indicates the age variable $(C$ value $=0.66), x 3$ (the green line) indicates marital status $(C$ value $=0.70), x 7$ (the brown line) indicates primary cancer type $(C$ value $=0.6 \mathrm{I})$, and $x 12$ (the violet line) indicates physical well-being $(\mathrm{C}$ value $=0.72$ ). $(\mathbf{B})$ ROC Curves for the algorithm including the variable of age (model $\mathrm{I}$ (the blue line), $\mathrm{C}$ value $=0.84)$ and the algorithm excluding the variable of age (model 2 (the red line), $C$ value $=0.82$ ).

slow growth cancer group, hormone-independent prostate cancer and lung cancer treated with molecularly targeted drugs were assigned to moderate growth cancer group, and lung cancer without molecularly targeted drugs was assigned to rapid growth cancer group. We found that this classification of primary cancer type possesses significance with postoperative anxiety and depression.

The six physical well-being items included pain, tiredness, nausea, drowsiness, lack of appetite, and dyspnea, which was a part of the Edmonton Symptom Assessment 
Table 5 C Value, Sensitivity, Specificity, FPR, and FNR of the Model with or Without Age

\begin{tabular}{|l|l|l|l|l|l|l|l|}
\hline Evaluation Analysis & AUROC & CCR & Sensitivity & Specificity & FPR & FNR & Goodness-of-Fit Test \\
\hline Model $^{\prime}$ & 0.84 & $81.3 \%$ & $61.5 \%$ & $84.8 \%$ & $57.9 \%$ & $7.5 \%$ & 0.76 \\
Model $^{2}$ & 0.82 & $70.2 \%$ & $53.8 \%$ & $73.1 \%$ & $73.6 \%$ & $10.2 \%$ & 0.06 \\
\hline
\end{tabular}

Notes: 'Indicates model including age. ${ }^{2}$ Indicates model excluding age.

Abbreviations: AUROC, area under the receiver operating characteristic curve; CCR, correct classification rate; FPR, false positive rate; FNR, false negative rate.

System (ESAS). ESAS was a useful tool to screen patients with anxiety and depression with the sensitivity and specificity of $86 \%$ and $56 \%$, respectively, for evaluating anxiety, and $97 \%$ and $43 \%$, respectively, in assessing depression. ${ }^{32}$ Besides, the pain has been shown to be independent with anxiety and depression in many other studies. ${ }^{33-35}$ In the study, when a patient had at least three items, we classified the patients into the group with poor physical well-being. We also found that this classification of the six physical well-being items was significantly associated with postoperative psychological distress.

Furthermore, we developed and validated a risk algorithm based on the above-mention four significant variables. This risk mode ranged from 0 to 24 points. Patients could be classified into three risk groups: patients in the group A had scores of 0 to 9 , and the rate of postoperative emotional distress was only $1.14 \%$, patient in the group $\mathrm{B}$ had scores of 10 to 15 , and the rate of postoperative emotional distress was $21.31 \%$, and patient in the group $\mathrm{C}$ had scores of 16 to 24 , and the rate of postoperative emotional distress was up to $54.55 \%$. Therefore, the risk of postoperative anxiety and depression was successfully stratified according to the risk algorithm. Patients in the group A were less likely to develop postoperative anxiety and depression, and patients in the group B were moderate to develop postoperative anxiety and depression. Therefore, more attention about mental health should be given to patients in the group B. Notably, patients in the group $\mathrm{C}$ had a high risk of postoperative emotional distress and psychological interventions, such as psychological counseling, should be performed in those patients during perioperative periods. An increasing number of studies had indicated that psychological interventions were critical regarding reducing emotional distress, facilitating adjustment, and improving the patient's quality of remaining life. Therefore, psychosocial interventions were increasingly regarded as an essential component of the comprehensive healthcare of cancer patients. Those psychological interventions mainly included cognitive-behavioral therapy, communication skills training, problem-solving therapy, stress management training, counseling, and music therapy. ${ }^{36}$ Besides, 32\% of intervention providers were psychologists, followed by nurses $(11 \%) .{ }^{37}$

In the study, $15.20 \%$ of patients had postoperative emotional distress. However, according to literature, studies reported that $29-55 \%$ of advanced cancer patients suffered from depression, ${ }^{5,6}$ and $44-65 \%$ of patients had anxiety. ${ }^{6,7}$ These numbers were higher than that in our studies. Firstly, the above-mentioned studies used different tools to measure the patient's emotional state, including Edmonton Symptom Assessment System (ESAS), 6,7 Hamilton anxiety rating scale (HARS), and the Beck anxiety inventory (BAI). ${ }^{38}$ Different tools would lead to different results. Secondly, the definition of anxiety and depression, evaluated by HADS, was also changed. In a meta-analysis on 46 studies, Hotopf et $\mathrm{al}^{5}$ found advanced cancer patients had a median prevalence of definite depression (ie, a score on the HADS depression subscale of $>10$ ) of $29 \%$. But studies that used psychiatric interviews indicated a prevalence of major depressive disorder ranging from $5 \%$ to $26 \%$, with a median of $15 \%$, which was consistent with our study. A study conducted by Delgado-Guay and his colleagues found $37 \%$ of the patients had depressive mood (HADS-depression $\geq 8$ ), and $44 \%$ had anxiety (HADS-anxiety $\geq 8$ ). ${ }^{7}$ In our study, we defined the diagnosis of emotional distress as a combined score of the HADS-anxiety and HADS-depression of 19 or more, since the sensitivity and the specificity were $68 \%$ and $67 \%$, respectively, according to the literature. ${ }^{21}$

This study has limitations. First, patients with incomplete records were not included in the study. However, nonresponders were more likely to develop anxiety and depression. ${ }^{14}$ Second, some variables, such as social support and psychotropic drugs, which were reported to be significant with anxiety and depression, were not included and analyzed in the study. Therefore, future studies should include other potential significant variables to investigate the association with postoperative anxiety and depression. Third, the mechanisms of postoperative emotional distress in advanced cancer patients were not easy to understand, and 
doctors and nurses should not only rely on the risk algorithm alone to implement treatments. The patient's personal intentions may be various and should also be respected. Fourth, in order to guarantee the homogeneity of patients, we did not enroll patients treated with conservative therapies. The applicability of the algorithm in patients treated with conservative therapies needs further investigations. Therefore, although this risk algorithm can effectively screen patients at high risks of postoperative emotional problems, it still needs a larger sample size to validate.

\section{Conclusion}

Postoperative emotional distress is common in patients with the metastatic spinal disease after surgery. We propose and validate an algorithm that can be used as a potential screening tool to identify patients at high risk of postoperative emotional distress.

\section{Funding}

This study was supported by Sanya's medical and health science and technology innovation project (NO. 2018YW04) and Nursing Department of Chinese PLA General Hospital (No. 2020YH25).

\section{Disclosure}

The authors declare that they have no conflict of interest for this work.

\section{References}

1. Feng RM, Zong YN, Cao SM, Xu RH. Current cancer situation in China: good or bad news from the 2018 global cancer statistics? Cancer Commun. 2019;39(1):22. doi:10.1186/s40880-019-0368-6

2. Bray F, Ferlay J, Soerjomataram I, Siegel RL, Torre LA, Jemal A. Global cancer statistics 2018: GLOBOCAN estimates of incidence and mortality worldwide for 36 cancers in 185 countries. CA Cancer J Clin. 2018;68(6):394-424. doi:10.3322/caac.21492

3. Abrahm JL, Banffy MB, Harris MB. Spinal cord compression in patients with advanced metastatic cancer: "all I care about is walking and living my life". JAMA. 2008;299(8):937. doi:10.1001/ jama.299.8.937

4. Patchell RA, Tibbs PA, Regine WF, et al. Direct decompressive surgical resection in the treatment of spinal cord compression caused by metastatic cancer: a randomised trial. Lancet. 2005;366 (9486):643-648. doi:10.1016/S0140-6736(05)66954-1

5. Hotopf M, Chidgey JHJ, Ly KL. Depression in advanced disease: a systematic review part 1 . Prevalence and case finding. Palliat Med. 2002;16(2):81-97. doi:10.1191/02169216302pm507oa

6. Salvo N, Zeng L, Zhang L, et al. Frequency of reporting and predictive factors for anxiety and depression in patients with advanced cancer. Clin Oncol. 2012;24(2):139-148. doi:10.1016/j.clon.2011.05.003

7. Delgado-Guay M, Parsons HA, Li Z, Palmer JL, Bruera E. Symptom distress in advanced cancer patients with anxiety and depression in the palliative care setting. Support Care Cancer. 2009;17(5):573-579. doi:10.1007/s00520-008-0529-7
8. Tatsuo A, Toru O, Yuriko S, Tomohito N, Yasuo S, Yosuke U. Major depression, adjustment disorders, and post-traumatic stress disorder in terminally ill cancer patients: associated and predictive factors. J Clin Oncol. 2004;22(10):1957-1965. doi:10.1200/ JCO.2004.08.149

9. Roth AJ, Massie MJ. Anxiety and its management in advanced cancer. Curr Opin Support Palliat Care. 2007;1(1):50-56. doi:10.1097/SPC.0b013e32813aeb23

10. Brintzenhofe-Szoc KM, Levin TT, Li Y, Kissane DW, Zabora JR. Mixed anxiety/depression symptoms in a large cancer cohort: prevalence by cancer type. Psychosomatics. 2009;50(4):383-391. doi:10.1176/appi.psy.50.4.383

11. Massie MJ. Prevalence of depression in patients with cancer. $J$ Natl Cancer Inst Monogr. 2004;2004(32):57-71. doi:10.1093/jncimonographs/lgh014

12. Smith EM, Gomm SA, Dickens CM. Assessing the independent contribution to quality of life from anxiety and depression in patients with advanced cancer. Palliat Med. 2003;17(6):509. doi:10.1191/ 0269216303pm781oa

13. Nordin K, Berglund G, Glimelius B, Sjödén PO. Predicting anxiety and depression among cancer patients: a clinical model. Eur J Cancer. 2001;37(3):376-384. doi:10.1016/S0959-8049(00)00398-1

14. Vliet QMJVD, Pereira NRP, Janssen SJ, et al. What factors are associated with quality of life, pain interference, anxiety, and depression in patients with metastatic bone disease? Clin Orthop Relat Res. 2016;475(2):1-10.

15. Choi D, Pavlou M, Omar R, et al. A novel risk calculator to predict outcome after surgery for symptomatic spinal metastases; use of a large prospective patient database to personalise surgical management. Eur J Cancer. 2018;107:28-36. doi:10.1016/j.ejca. 2018.11.011

16. Tokuhashi Y, Uei H, Oshima M, Ajiro Y. Scoring system for prediction of metastatic spine tumor prognosis. World J Orthop. 2014;5 (3):262-271. doi:10.5312/wjo.v5.i3.262

17. Tokuhashi Y, Matsuzaki H, Oda H, Oshima M, Ryu J. A revised scoring system for preoperative evaluation of metastatic spine tumor prognosis. Spine. 2005;30(19):2186-2191. doi:10.1097/01.brs.00001 80401.06919.a5

18. Rades D, Staackmann C, Janssen S. Predicting the ambulatory status of patients irradiated for metastatic spinal cord compression (MSCC) from head-and-neck cancer. Anticancer Res. 2018;38(8):4833-4837. doi:10.21873/anticanres.12794

19. Rades D, Rudat V, Veninga T, et al. A score predicting posttreatment ambulatory status in patients irradiated for metastatic spinal cord compression. Int J Radiat Oncol Biol Phys. 2008;72(3):905-908. doi:10.1016/j.ijrobp.2008.02.018

20. Zigmond AS, Snaith RP. The hospital anxiety and depression scale. Acta Psychiatr Scand. 1983;67(6):361-370. doi:10.1111/j.16000447.1983.tb09716.x

21. Lloyd-Williams M, Friedman T, Rudd N. An analysis of the validity of the hospital anxiety and depression scale as a screening tool in patients with advanced metastatic cancer. $J$ Pain Symptom Manage. 2001;22(6):990-996. doi:10.1016/S0885-3924(01)00358-X

22. Carey M, Noble N, Sanson-Fisher R, Mackenzie L. Identifying psychological morbidity among people with cancer using the hospital anxiety and depression scale: time to revisit first principles? PsychoOncology. 2012;21(3):229-238. doi:10.1002/pon.2057

23. Beck KR, Tan SM, Lum SS, Lim LE, Krishna LK. Validation of the emotion thermometers and hospital anxiety and depression scales in Singapore: screening cancer patients for distress, anxiety and depression. Asia Pac J Clin Oncol. 2016;12(2):e241-249. doi:10. 1111/ajco.12180

24. Lei M, Li J, Liu Y, Jiang W, Liu S, Zhou S. Who are the best candidates for decompressive surgery and spine stabilization in patients with metastatic spinal cord compression? Spine. 2016;41 (18):1469-1476. doi:10.1097/BRS.0000000000001538 
25. Schag CC, Heinrich RL, Ganz PA. Karnofsky performance status revisited: reliability, validity, and guidelines. J Clin Oncol. 1984;2 (3):187-193. doi:10.1200/JCO.1984.2.3.187

26. Frankel HL, Hancock DO, Hyslop G, et al. The value of postural reduction in the initial management of closed injuries of the spine with paraplegia and tetraplegia. Paraplegia. 1969;7(3):179-192. doi:10.1038/sc. 1969.30

27. Hanley J, McNeil B. The meaning and use of the area under a receiver operating characteristic (ROC) curve. Radiology. 1982;143:29-36. doi:10.1148/radiology.143.1.7063747

28. Weiss Wiesel TR, Nelson CJ, Tew WP, et al. The relationship between age, anxiety, and depression in older adults with cancer Psycho-Oncology. 2015;24(6):712. doi:10.1002/pon.3638

29. Mor V, Allen S, Malin M. The psychosocial impact of cancer on older versus younger patients and their families. Cancer. 2015;74 (S7):2118-2127.

30. Blank TO, Bellizzi KM. A gerontologic perspective on cancer and aging. Cancer. 2008;112(11 Suppl):2569-2576. doi:10.1002/cncr.23444

31. Gonzalez-saenz de Tejada M, Bilbao A, Baré M, et al; Group CC. Association between social support, functional status, and change in health-related quality of life and changes in anxiety and depression in colorectal cancer patients. Psycho-Oncology. 2017;26(9):1263. doi:10.1002/pon.4303

32. Vignaroli E, Pace EA, Willey J, Palmer JL, Zhang T, Bruera E. The edmonton symptom assessment system as a screening tool for depression and anxiety. J Palliat Med. 2006;9(2):296. doi:10.1089/jpm.2006.9.296
33. Mystakidou K, Tsilika E, Parpa E, Katsouda E, Galanos A, Vlahos L. Assessment of anxiety and depression in advanced cancer patients and their relationship with quality of life. Qual Life Res. 2005;14 (8):1825-1833. doi:10.1007/s11136-005-4324-3

34. Ciaramella A, Poli P. Assessment of depression among cancer patients: the role of pain, cancer type and treatment. Psycho-oncology. 2001;10(2):156. doi:10.1002/pon.505

35. Massie MJ, Holland JC. Depression and the cancer patient. J Clin Psychiatry. 1990;51(7):12-17.

36. Jacobsen PB, Jim HS. Psychosocial interventions for anxiety and depression in adult cancer patients: achievements and challenges. CA Cancer J Clin. 2008;58(4):214-230. doi:10.3322/CA.2008. 0003

37. Salsman JM, Pustejovsky JE, Schueller SM, et al. Psychosocial interventions for cancer survivors: a meta-analysis of effects on positive affect. J Cancer Surviv. 2019;13(6):943-955. doi:10.1007/ s11764-019-00811-8

38. Leentjens AF, Dujardin K, Marsh L, Richard IH, Starkstein SE, Martinez-Martin P. Anxiety rating scales in Parkinson's disease: a validation study of the Hamilton anxiety rating scale, the Beck anxiety inventory, and the hospital anxiety and depression scale. Mov Disord. 2011;26(3):407-415. doi:10.1002/mds.23184
Psychology Research and Behavior Management

\section{Publish your work in this journal}

Psychology Research and Behavior Management is an international, peer-reviewed, open access journal focusing on the science of psychology and its application in behavior management to develop improved outcomes in the clinical, educational, sports and business arenas. Specific topics covered in the journal include: Neuroscience, memory and decision making; Behavior modification and management; Clinica applications; Business and sports performance management; Social and developmental studies; Animal studies. The manuscript management system is completely online and includes a very quick and fair peer-review system, which is all easy to use. Visit http://www. dovepress.com/testimonials.php to read real quotes from published authors. 